\title{
MÍDIAS E A IMAGEM CORPORAL NA ADOLESCÊNCIA: O CORPO EM DISCUSSÃO
}

\author{
Erica Frois ${ }^{\star}$ \\ Jacqueline Moreira" \\ Márcia Stengel ${ }^{\Uparrow}$
}

\begin{abstract}
RESUMO. O presente artigo busca discutir a influência da mídia sobre as imagens advindas dos modelos contemporâneos de valorização da adolescentização das idades e a organização da imagem corporal do jovem. Entende-se como adolescentização o processo de valorização de características tipicamente adolescentes, como a apropriação e a construção de uma identidade corporal e a experimentação de novas referências corporais. A partir dessa discussão, pretende-se propor análises do jovem na contemporaneidade e de seus modos possíveis de construir uma imagem corporal que favoreça seu bem-estar na relação com os outros. O presente estudo apresenta uma reflexão teórica de cunho especulativo a partir de autores clássicos que abordam a adolescência, como Aberastury e Knobel, Kehl e outros.
\end{abstract}

Palavras-chave: Imagem corporal; contemporaneidade; adolescência.

\section{MEDIA AND BODY IMAGE IN ADOLESCENCE: THE BODY IN DISCUSSION}

\begin{abstract}
The aim of this article is to discuss the influences of the media on the images that come from the contemporary models of valuing the adolescence age and the organization of the youth's people body image. The term adolescence age, in this sense, refers to the process of valuing characteristics typical of adolescents, such as the appropriation and construction of a body identity and the experimentation with new body references. Based on this discussion, we intend to propose analysis about the youth in contemporaneity and their ways of possible constructions of a body image that promotes the subject's welfare when relating to others. This study presents a theoretical discussion, in a speculative way, from classical authors that discuss adolescence as Aberstury and Knobel, as well as Kehl and others.
\end{abstract}

Key words: Body image; contemporaneity; adolescence.

\section{MEDIOS DE COMUNICACIÓN Y LA IMAGEN CORPORAL EN LA ADOLESCENCIA: EL CUERPO EN EL DEBATE}

RESUMEN. El presente artículo busca discutir la influencia de los medios de comunicación, , los imágenes que provienen de los modelos contemporaneos de valoración de la adolescentización de las edades de la vida y la organización del imagen corporal de los jóvenes. Se entiende como adolescentización el proceso de apreciación de características típicamente adolescentes, como la apropiación y la construcción de una identidad corporal y la experimentación de nuevas referencias corporales. A partir de esa discusión, se pretende proponer un análisis del joven en la contemporaneidad y sus modos de construcciones posibles de un imagen corporal que promueve el bienestar del sujeto en relación con los demás. Este estudio presenta una discusión teórica de carácter especulativo de los autores clásicos que hablan de la adolescencia, Aberastury y Knobel, Kehl y otros.

Palabras-clave: Imagen corporal; contemporaneidad; adolescencia.

O presente estudo tem como objetivo propor discussões a respeito da influência das mídias sobre a imagem corporal na adolescência. Por meio de uma reflexão teórica de caráter especulativo o texto delineia-se a partir de autores clássicos da psicologia, da adolescência e de outras contribuições sobre o

Mestre em Psicologia pela Pontifícia Universidade Católica de Minas Gerais. Professora Titular da Pontifícia Universidade Católica de Minas Gerais , Brasil.

\# Doutora em Psicologia (Psicologia Clínica) pela Pontifícia Universidade Católica de São Paulo. Professora Adjunta III da Pontifícia Universidade Católica de Minas Gerais , Brasil.

I Doutorado em Ciências Sociais pela Universidade do Estado do Rio de Janeiro, Brasil(2004).Professora Adjunta III da Pontifícia Universidade Católica de Minas Gerais, Brasil 
adolescente, a mídia e a cultura contemporânea, embora ele não tenha o intuito de apresentar uma visão finalista sobre o assunto, mas de convidar o leitor a realizar reflexões e discussões a partir do material apresentado.

\section{IMAGEM CORPORAL E RELAÇÕES PRIMORDIAIS}

Pensar na construção da imagem corporal pressupõe uma leitura sobre a relação do sujeito com o mundo que envolve uma articulação harmônica entre as dimensões física, psíquica e social do corpo. Embora alguns autores considerem quase como sinônimos e outros como termos distintos os constructos imagem corporal e esquema corporal, propõe-se nesse estudo romper como uma visão fragmentada das funções do corpo biológico $\mathrm{X}$ corpo psicoafetivo. Interessa abordar a relação do adolescente com sua percepção corporal e relacional, implicando um constante entrelaçamento das dimensões biológica, psíquica, social e inter-humana como constituintes do indivíduo. Deste modo, ao pensar sobre a imagem corporal é preciso esclarecer determinados termos. Para alguns autores, como Meur (1989) e Coste (1992), imagem e esquema corporal são funções distintas que ora se aproximam ora se distanciam, porém este estudo se propõe abordar tais funções em uma dinâmica integralizada, rompendo com a percepção isolada e fragmentada do corpo.

A partir de autores como Fischer (1990), Hart (2003), Schilder (1999) e Tavares (2003), pode-se compreender que a imagem corporal é um constructo que engloba as percepções do indivíduo sobre si mesmo e sobre a relação que ele mantém com os outros. Nesta medida, as demais funções - como o esquema corporal, a lateralidade e as noções espaciais e temporais - seriam todas componentes da imagem corporal. Na medida em que estas noções constituem o indivíduo na sua trama relacional elas estariam na dimensão formacional, compondo assim a imagem que o indivíduo tem de si a partir das suas percepções acerca da estrutura corporal, da aparência e da percepção que tem de como os outros o veem. Nessa medida a imagem corporal compõe o processo identitário e formacional do adolescente.

Assim, compreender como o indivíduo constrói a imagem do corpo, como ele se vê e como se relaciona com o mundo, depende das vivências que ele tenha construído a partir de suas experiências desde o nascimento. Os cuidados na infância, as relações com a mãe e outros indivíduos que nomeiam esse corpo atuam na construção da imagem corporal, permitindo que o indivíduo se defina como gordo, magro, alto ou baixo, por exemplo. "A imagem do corpo é a síntese viva de nossas experiências emocionais (...) é a memória inconsciente de todo o vivido relacional e, ao mesmo tempo, ela é atual, viva, em situação dinâmica, simultaneamente narcísica e inter-relacional" (Dolto, 1984, p. 15).

Nesta relação, a imagem corporal é construída a partir dos nomes que vamos incorporando ao nosso corpo e ao nosso modo de ser no mundo. Desde a gestação, ou mesmo no planejamento desta, a criança vai recebendo nomes imbuídos de sentidos e significações. Esses elementos contribuirão para a sua posterior apropriação de uma imagem corporal. Apesar, porém, de ser influenciada pelos nomes que recebe dos pais e cuidadores, ela passa a vivenciar e experimentar novas sensações após o seu nascimento, o que possibilita outras representações e significações para esse corpo. Experiências no mundo que a cerca lhe possibilitarão outras referências e a incorporação de novas noções de si própria, da significação do seu esquema corporal e do seu corpo em movimento. A essas experiências soma-se o contato infantil com a escola, com os colegas e com as mídias que a situam no mundo contemporâneo. Deste modo, as imagens do corpo vão sendo construídas e reconstruídas ao longo da vida do indivíduo, imbuindo-o de significações a partir das vivências que outras referências lhe apresentam. Trata-se de um processo cíclico e gradativo ao longo da vida, no qual as mudanças físicas e psíquicas do corpo suscitam a necessidade de constante reorganização da imagem corporal. Nas suas relações com o mundo, a criança vai se apropriando de significados e traduzindoos em movimentos do seu corpo na relação com os outros. Assim, as exigências traduzidas pelas imagens do contemporâneo, sobretudo as fornecidas pelas mídias, configuram um corpo-imagem irreal e ilusório, nem sempre convergente e em sintonia com as imagens corporais de indivíduos imbuídos de marcas familiares e vivenciais de ordem biológica, afetiva e social. Essa incongruência acaba por gerar um processo conflituoso, que será organizado a partir de um novo ajustamento da imagem corporal. A cada momento em que recebe novas demandas físicas e afetivas o indivíduo se vê na necessidade de construir novas imagens e esquemas para o seu corpo, de modo a colocar-se saudável na relação com os outros no mundo.

\section{IDEAIS SOCIAIS E IMAGEM CORPORAL}

Dentre as relações que vivencia o indivíduo, as mídias são elementos constantes enquanto referências que incidem nos nomes que a criança e seu corpo 
recebem, caracterizando uma demanda constante de ajustamento e reorganização das imagens e esquemas corporais. Sendo assim, a forma de apropriação da imagem corporal perpassa pelas definições que se obtêm a partir dos outros e das mídias - rádio, televisão e, sobretudo, internet, e, embora as construções da imagem corporal não estejam submetidas apenas às imposições das mídias, elas, assim como as demais experiências pelas quais passa a criança, influem na sua formação.

Rizzini et al. (2005), em pesquisa sobre a influência das mídias televisão, videogame, jogos para computador, internet e telefone celular na vida dos adolescentes, concluíram que a televisão é o meio de comunicação de massa mais difundido, seguida do computador e da internet. Já Levy (1999) afirma que as novas tecnologias de comunicação estão difundidas na contemporaneidade por meio da internet e da televisão, mas também das agências bancárias, lojas e outros serviços presentes nas cidades. Desse modo percebe-se que a influência midiática é um importante veículo formacional e constituinte do indivíduo.

Assim as mídias, principalmente a televisão e a internet, têm influído na divulgação e valorização do corpo perfeito. Entre sites de agências de beleza, comunidades virtuais que valorizam o culto aos músculos e a conquista de corpos cada vez mais magros e rejuvenescidos, observa-se o constante aumento da busca pelo ideal de um corpo moldado e esculpido que esconde as marcas do tempo e as vivências a que o sujeito está submetido. As mídias demarcam e refletem, a todo o momento, lugares, espaços e definições que influenciam os indivíduos, apontando para a formação de imagens nem sempre condizentes com uma imagem corporal já por eles construída. Desta maneira, a imagem do corpo aparece como incongruente com as demais imagens reveladas pelas mídias, que abarcam símbolos representativos da contemporaneidade: busca imediata por corpos esculpidos e artificializados, sinais de status e perfeição. Damasceno et al. (2006) afirmam que a insatisfação com a imagem corporal aumenta à medida que a mídia expõe belos corpos, fato que nas últimas décadas tem provocado uma compulsão a buscar a anatomia ideal.

Segundo Rubim (2000), a contemporaneidade pode ser definida como um período histórico caracterizado a partir das marcas capitalistas globalizadas, consumistas, industriais e cibernéticas, apontando um contexto comunicacional abrangente, situado no século XX; mas é importante enfatizar que a incongruência entre a imagem real e o ideal de imagem do corpo e a valorização de um tipo ideal de corpo não constituem uma exclusividade deste momento histórico. Encontramos, por exemplo, relatos de quadros de anorexia no século XIX, como o da imperatriz da Áustria Elisabeth von ÖsterreichUngarn, Princesa Sissi.

Essa distância entre o corpo real e a imagem corporal é fenômeno estruturante do sujeito, pois a todo o momento as inscrições iniciais feitas nas suas primeiras relações com o mundo se veem confrontadas pelas novas imagens que o mundo apresenta ao indivíduo. Em todos os períodos históricos há modelos desejados e seguidos pela sociedade: modelos de família, de beleza feminina, de status masculino e outros, mas a questão não está na incongruência entre referenciais e desejos - afinal, a busca se projeta sobre uma falta. A reflexão para localizarmos o jovem e a construção de sua corporeidade está no fato de as exigências fantasiosas, fantásticas e cyborescas ${ }^{1}$ impulsionarem os jovens para uma possível concretização. A viabilização real desses modelos, sobrepujando uma imagem corporal com base em experiências afetivas, biológicas e estruturais, acaba suscitando conflitos e inconformidades na vida do jovem. A imagem corporal advinda da infância não é determinística, mas apriorística, pois marca o lugar do sujeito no espaço, apontando para uma identidade que configura o contato entre sujeito e mundo - logo é a partir da construção de uma nova imagem corporal por meio de vivências, e não de montagens externas e estereotipadas, que o jovem poderá se colocar de modo saudável na relação com o mundo.

Guzzo (2005) afirma, citando Haraway (1991), que o termo cyborg abarca o mito de superação das dicotomias do corpo. Tais dicotomias traduzem as incongruências, os conflitos e as transformações que permeiam o desenvolvimento humano e são negados a partir da idealização e busca de construção do corpo perfeito. $\mathrm{O}$ homem, nesse contexto, estaria procurando superar as limitações desse corpo, equiparando-o à máquina, podendo viver como num sonho em um mundo sem dualismos.

O cyborg é um organismo cibernético, uma criatura de ficção científica e de realidade social. É o corpo transformado em matéria híbrida: uma mistura de organismo e máquina. Esse novo corpo une-se à nova configuração da realidade transformada pela reprodução cibernética e reestruturada pela influência da mediação eletrônica repleta de riscos. (Guzzo, 2005, p. 147)

\footnotetext{
Adjetivação feita a partir do termo cyborg, definido por
} Donna Haraway (1991) e citado por Guzzo (2005). 
Assim, segundo Guzzo (2005), esse mito tem subsidiado o imaginário dos indivíduos, incidindo em suas buscas e efetivações de tentativas de um corpo perfeito por meio de cirurgias e do enxerto de substâncias.

Dessa forma, na contemporaneidade, a questão da corporeidade não aponta para o antigo dilema de corpo desejado e corpo estruturado, mas direciona-se à concretização dos desejos mais diversos e longínquos possíveis da realidade, sobrepujando questões estruturais da ordem da imagem e do esquema corporal. Assim, o desejo de efetivar mudanças no corpo pode ser legítimo, levando as pessoas a mudar hábitos, reconstruir seus modos de se verem no mundo e se colocar neste de forma mais efetiva e saudável. Mudar hábitos alimentares e fazer exercícios físicos são exemplos de ações contemporâneas que nos dias atuais se acredita serem contribuintes processuais para as mudanças exigidas para uma melhor qualidade de vida, o que resulta em readaptações à imagem e ao esquema corporal dos indivíduos. Nesse sentido, percebe-se que ambos, imagem e esquema corporal, modificam-se ao longo da história do indivíduo, e que as mudanças são processuais, acompanhando uma reestruturação adaptativa entre imagem e esquema corporal.

Os belos corpos, sempre esculpidos, magros e rejuvenescidos, estão a serviço do consumo e refletem o desejo de uma sociedade que busca no imediatismo a eternização da juventude. São corpos-imagem que se definem como estampa idealizada e ilusória pautada em um processo de projeção do corpo promovido pelas mídias. O foco está na aparência que o corpo traduz e nos símbolos contemporâneos de valorização: imediatismo, juventude, liberdade, magreza e músculos proeminentes e definidos. Percebe-se que nesse processo estão envolvidas toda uma sociedade e suas idades de vida, de bebês a idosos, havendo sempre um ideal de imagem diferente daquela que se apresenta na realidade, o que, aos olhos de alguns autores do século XX, seria uma das características evidentes de adolescentes típicos.

\section{IMAGEM CORPORAL NA ADOLESCÊNCIA E OS IDEAIS SOCIAIS}

Aberastury e Knobel (1981), ao dedicarem-se a estudos sobre o desenvolvimento do adolescente, descrevem mudanças físicas e afetivas características desta fase, entre elas a busca de si mesmo e da identidade, a deslocalização temporal e o luto pelo corpo infantil. Tais mudanças são demonstrativas da forma como os adolescentes lidam com processo de modificação corporal e hormonal advindo da puberdade e com o processo de ajustamento que essas novas demandas evocam. O conflito entre a busca de uma identidade adulta que implique autonomia e o desejo de prosseguir no amor e na dependência das crianças pode se apresentar por meio da insatisfação do jovem diante do corpo. Osório (1989) afirma que o adolescente vive um dilema existencial na busca por uma apropriação de uma identidade diferente advinda daquela da infância, pois novas demandas surgem na adolescência, suscitando novos conhecimentos de si:

\begin{abstract}
Identidade é o conhecimento por parte de cada indivíduo da condição de ser uma unidade pessoal ou entidade separada e distinta dos outros, permitindo-lhe reconhecer-se o mesmo a cada instante de sua evolução ontológica e correspondendo ao plano social, resultante de todas as identificações prévias feitas até o momento considerado. (Osório, 1989, p. 15)
\end{abstract}

Nessa busca, o adolescente se vê diante de novas demandas de ordem afetiva, hormonal e física. A imagem corporal precisará ajustar-se às novas demandas do jovem. Nesse processo de ajustamento, Osório (1989) aponta que a insatisfação do jovem com o seu corpo é característica da estranheza e da ansiedade diante das mudanças surgidas: "É reconhecida a insatisfação dos adolescentes com sua aparência física. A percepção das constantes mudanças ocorridas no corpo é a responsável pela frequência com que ocorrem os sentimentos de estranheza do próprio self na adolescência." (p. 16) Assim, esse processo pode trazer conflitos ao jovem, os quais tendem a diminuir à medida que $\mathrm{o}$ adolescente reorganiza sua imagem corporal. Nesse processo de adaptação a partir de novas demandas corporais é comum que as imagens preferidas e valorizadas no mundo colaborem para o acirramento dos conflitos e das angústias do adolescente, de modo que o conflito entre imagem corporal e corpos-imagem é inevitável na adolescência e, em certa medida, é estruturante e benéfico no processo de apropriação da identidade do adolescente.

Nesse processo de construção e reconstrução cíclica da imagem corporal situam-se todos - crianças, jovens, adultos e idosos; mas é na adolescência que se dá um processo de luto típico do corpo infantil, o que permite uma mudança significativa do posicionamento do corpo no mundo. Assim, ainda que o processo de reconstrução da imagem corporal seja uma possibilidade constante ao longo da vida, é na adolescência que essa demanda se torna irrefutável, 
pois as incongruências apresentadas não giram em torno apenas do desejo de se ter um corpo diferente do que se tem, mas apontam para uma mudança inexorável do corpo impelida por questões hormonais e físicas, suscitando no indivíduo demandas de ajustamento estruturais.

\begin{abstract}
A perda que o adolescente deve aceitar ao fazer o luto pelo corpo é dupla: a de seu corpo de criança, quando os caracteres sexuais secundários colocam-no ante a evidência de seu novo status e o aparecimento da menstruação na moça e do sêmen no rapaz, que lhes impõem o testemunho da definição sexual e do papel que terão de assumir, não só na união com o parceiro, mas também na procriação. (Aberastury \& Knobel, 1981, p. 64)
\end{abstract}

Dessa forma, embora seja um processo da vida a reconstrução da imagem corporal, é na adolescência que esta se dá de modo estruturante, configurando a conquista de uma identidade corporal que propõe, na melhor das hipóteses, um desfecho com uma corporeidade bem-estruturada e equilibrada na relação com o mundo. Assim, a necessidade de ajustar a imagem corporal a novas demandas deve ser seguida pela correspondente reorganização dessa imagem, promovendo estabilidade do corpo e consequente reposicionamento no mundo. Segundo Aberastury (1981), citada por Aberastury e Knobel (1981), para que os jovens se organizem diante desse conflito e recomponham a própria imagem corporal, eles precisam dimensionar um luto pelo corpo infantil, contrapor-se aos modelos parentais infantis e, dessa maneira, apropriar-se dos modelos próprios de identificação. Nesse percurso os jovens buscam figuras idealizadas que se contrapõem aos modelos parentais e nele se situam os modelos de corpo ideais que o mundo fornece. Os adolescentes, então, passam a desejar novas roupas e acessórios, outros espaços, vínculos e novos corpos. Buscam novos paradigmas e a definição de uma identidade corporal. Nesse processo, constroem idealizações a partir de outras figuras identificatórias, mas é a partir de figuras parentais seguras e satisfatórias - que atuam com limites claros, indicando uma autoridade razoável e sustentando uma imagem corporal - que o adolescente pode buscar uma oposição, desejar novos paradigmas $\mathrm{e}$, posteriormente, apropriar-se de uma identidade corporal. Ter pais com uma organização da própria corporeidade não conflitiva, em harmonia com o modo como se vê e se relaciona no mundo, é um indicativo para saídas saudáveis para os adolescentes diante dos conflitos entre imagem corporal e corpos-imagem.
Não obstante, o que dizer de um contexto no qual todos os segmentos - crianças, jovens, adultos e idosos - seguem num dilema constante entre imagem corporal e corpos-imagem?; de um contexto no qual a todo instante todos precisam readaptar seus corpos sem se encontrarem num ajustamento e estabilização da imagem corporal e continuam vivendo um conflito típico e característico da adolescência?

O conflito entre imagem corporal e corpoimagem, que acarreta o desejo por um corpo diferente do que se possui, não é um fato novo e também em si não constitui um problema. A questão é quando uma característica, a princípio necessariamente transitória, perpassa como padrão. Nessa medida, como o jovem poderá construir uma identidade corporal satisfatória para si, uma imagem corporal congruente com suas vivências, percepções e subjetividades, se não tem padrões estáveis, sobretudo parentais, para se contrapor, apropriar-se e se definir numa corporeidade? Como poderá construir uma identidade, se as referências não são estáveis?

Essas questões denotam a fragilização dos marcos sociais - referenciais políticos, familiares, institucionais - para que o adolescente possa se contrapor e construir suas próprias marcas estruturais e definidoras da sua identidade em direção ao mundo adulto. Como definir-se garantindo certa estabilidade corporal sem ter um modelo adulto baseado na estabilidade para espelhar-se? A perspectiva transitória e de experimentação de situações e identidades é uma característica típica dos adolescentes, mas ela tem se apresentado na contemporaneidade como estereótipo valorizado, aceito e perseguido por pessoas de todas as idades. Nesse sentido, como tornar-se um adulto definindo-se enquanto figura mais estável, de referência para o jovem? Este tipo de questão parece sustentar um convite à reflexão sobre novos paradigmas para os conceitos de identidade, adolescência e idade adulta que, por extrapolarem os objetivos desse artigo, não serão aqui melhor explorados.

Faz-se necessária, não obstante, uma breve análise desse processo de "adolescentização" da sociedade contemporânea, pois a valorização desses atributos típicos do jovem, ao estender-se às demais idades de vida, acaba por trazer outros complicadores para além das dificuldades de construção da identidade adulta a partir da idealização do corpo jovem. Aponta também para uma busca constante de outros atributos adolescentes, tais como experimentações sem compromisso, imediatismo e consumo.

Kehl (2007) afirma que a transformação do adolescente em fatia privilegiada do mercado 
consumidor, inaugurada nos Estados Unidos e difundida no mundo capitalista, traz a valorização de um modelo nunca antes prescrito socialmente. Jovens acabrunhados, revolucionários, desajeitados, de pele acneica e isolados socialmente transformaram-se em ícones de beleza e liberdade, podendo gozar de status sem incorrer no ônus disso.

$\mathrm{O}$ adolescente das últimas décadas do século XX deixou de ser a criança grande, desajeitada e inibida, de pele ruim e hábitos anti-sociais, para se transformar no modelo de beleza, liberdade e sensualidade para todas as outras faixas etárias. O adolescente pós-moderno desfruta de todas as liberdades da vida adulta, mas é poupado de quase todas as responsabilidades. (Kehl, 2007, p. 46)

Kehl (2007) define, ainda, pontos contundentes que nos permitem refletir sobre novos parâmetros para contextualizar a adolescência na contemporaneidade. Enquanto Osório (1989) propõe que a adolescência é uma etapa evolutiva peculiar ao desenvolvimento humano, e que ela contempla o desenvolvimento maturativo biopsicossocial do indivíduo, Kehl (2007) questiona referenciais anteriores que entediam a adolescência apenas como uma etapa de transição para a vida adulta e propõe uma reflexão acerca da adolescência enquanto ícone valorizado e almejado por todas as idades da vida. Trata-se de um estado da vida no qual são permitidas experimentações respaldadas por uma aceitação de instabilidades, indefinições e dependência financeira e emocional para com os pais:

O aumento progressivo do período de formação escolar, a alta competitividade do mercado de trabalho nos países capitalistas e, mais recentemente, a escassez de empregos obrigam o jovem adulto a viver cada vez mais tempo na condição de adolescente, dependente da família, apartado das decisões e responsabilidades da vida pública, incapaz de decidir seu destino. (Kehl, 2007, p. 44)

A autora pontua, ainda, a indústria cultural e o consumo como elementos marcantes na sociedade contemporânea, incidindo em uma imagem valorizada da "adolescentização" da população: "Quanto mais tempo pudermos nos considerar jovens hoje em dia, melhor. Melhor para a indústria de quinquilharias descartáveis, melhor para a publicidade. (...) Nas últimas décadas, viramos jovens perenes" (Kehl, 2007, p. 47).
Assim, sendo as referências da ordem do imediatismo, do vulnerável, do efêmero, essas demandas tendem a seguir como máximas de uma geração, suscitando questões da ordem da insatisfação do corpo, pois a falta de referências estáveis para um processo de reorganização saudável da imagem corporal compromete a estruturação da corporeidade do indivíduo, direcionando-o para uma imagem corporal perturbada. Um desajustamento do modo como o sujeito se vê não lhe permite colocar-se no mundo de forma saudável. A tentativa de valorizar uma imagem corporal a partir dos estereótipos da mídia perturba o processo de construção do adolescente, que se ancora em vivências e figuras parentais mais ou menos estáveis para se contrapor e definir identidades próprias. Em contrapartida, arcar psíquica, física e economicamente com a realização de novas imagens que se apresentam de modo estereotipado e volúvel torna-se insustentável.

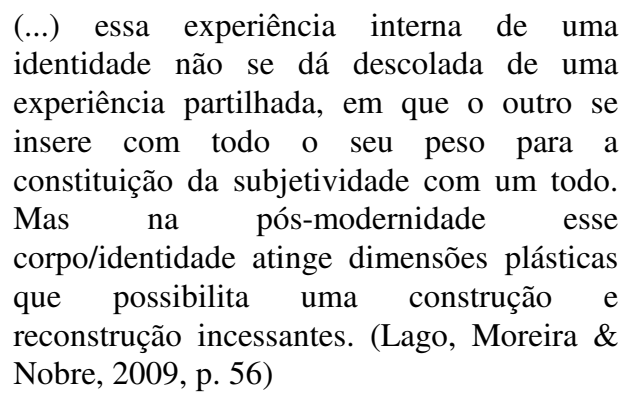
identidade não se dá descolada de uma experiência partilhada, em que o outro se insere com todo o seu peso para a constituição da subjetividade com um todo. Mas na pós-modernidade esse corpo/identidade atinge dimensões plásticas que possibilita uma construção e reconstrução incessantes. (Lago, Moreira \& Nobre, 2009, p. 56)

Tentar concretizar o sonho de um corpo-imagem é ilusório, e se, a partir da valorização desse ideal e das seduções, sobretudo das mídias, o indivíduo se vê impelido a buscar essa efetivação, os resultados não são promissores, não passando de frustrações, afastamento social, imperfeições, depressões ou morte.

Sendo assim, a questão se torna cíclica. Há nela um círculo vicioso a partir das efemeridades, imediatismos, busca de rejuvenescimento e falta de referenciais estáveis: quanto mais se valoriza a "adolescentização", mais se configuram jovens desestruturados, que, ao seguirem buscando uma referência e se vendo diante da valorização dos corpos-imagem ilusórios e efêmeros, não conseguem sustentar uma imagem corporal congruente e satisfatória para si mesmo. Acabam por tornar-se novos adeptos do culto aos corpos-imagem e, assim, reiniciam um novo ciclo; mas o caminho para viabilizar mudanças nesse circuito parece apontar para duas situações: questionar os padrões da ordem do imediatismo e da busca pela "adolescentização" social e por rever os novos paradigmas familiares, partindo de investigações situadas no mais clássico modelo 
predito pelos autores da psicologia do desenvolvimento adolescente: as referências parentais.

\section{CONSIDERAÇÕES FINAIS}

O processo de reconstrução de novas imagens corporais a partir do corpo vigente e dos corposimagem almejados ocorre ao longo de toda a vida e de modo típico na adolescência, sendo constituinte, estrutural e característico nessa fase; portanto processo de construção da imagem corporal é cíclico e perdura ao longo de toda a vida. O jovem, não obstante, por viver transformações biológicas, físicas, hormonais e psíquicas, enfrenta um processo crítico e importante da vida, o que demanda um arcabouço estruturante que o acompanhe nessa dinâmica. A autoridade organizadora dos pais e cuidadores tem papel primordial, pois contribui, a partir de vínculos estáveis e saudáveis, para um processo harmônico de construção de uma nova imagem corporal. Nessa medida, a perspectiva contemporânea do efêmero e do imediato, a idealização do corpo perfeito e a busca por corpos-imagem poderão localizar-se na dimensão do sonho adolescente, da construção fantasiosa que aos poucos se transforma, com as bordas de uma realidade adulta estável, em um universo sustentável na estabilidade corpórea a partir de uma imagem corporal embasada nas vivências construídas ao longo da vida.

Enfim, parece que essas reflexões a partir da imagem corporal na adolescência que se estendem a análises contundentes sobre a contemporaneidade e seus modos, políticos e sociais, de viver no mundo, podem suscitar saídas, e, embora essas reflexões sejam incapazes de sustentar respostas prontas e imediatas, demandas do contemporâneo podem oferecer entendimento e análises críticas capazes de apontar compreensões e caminhos possíveis diante do processo de construção da corporeidade do adolescente.
Damasceno, V. O., Vianna, V. R. A., Vianna, J. M., Lacio, M., Lima, J. R. P., \& Novaes, J. S. (2006). Imagem corporal e corpo ideal. Revista brasileira Ciência e Movimento, 14(1): 87-96.

Dolto, F. (1984). A imagem inconsciente do corpo. São Paulo: Perspectiva.

Fischer, S. (1990). The evolution of psychological concepts about the body. In Body Images: Development, deviance, and change (Cap.1, pp.3-10). New York: Guilford Press.

Guzzo, M. (2005). Riscos da beleza e desejos de um corpo arquitetado. Revista Brasileira de Ciência e Esporte, 27(1), 139152.

Hart, E. A. (2003). Avaliando a Imagem Corporal. In Medidas $e$ Avaliação em Educação Física e Esportes de Barrow \& McGee (pp.457-488) São Paulo: Ed. Manole.

Kehl, M. R. (2007). A juventude como sintoma da cultura. Revista Juventude: outro olhar, 5(6), 43-45.

Lago, G. C. P., Moreira, J. O., \& Nobre, M. R. (2009) A experiência do corpo no ciberespaço: o adolescer na era da realidade virtual (p. 56). Anais do CONPSI. Belém, Pa, 6.

Levy, P. (1999). Cibercultura. São Paulo: Editora 34.

Meur, A. (1989). Psicomotricidade: educação e reeducação; níveis maternal e jardim. São Paulo: Manole.

Osório, L. C. (1989). Adolescente hoje. Porto Alegre: Artes Médicas.

Rizzini, I., Pereira, L., Zamora, M. H., Coelho, A. F., Winograd, B., \& Carvalho, M. (2005). Adolescentes brasileiros, mídia e novas tecnologias. Revista ALCEU, 6(11), 41- 63. Recuperado em 22 maio, de 2009, de http://publique.rdc.pucrio.br/revistaalceu/media/Alceu_n11_Rizzini.pdf.

Rubim, A. A. C. (2000). A contemporaneidade como idade mídia. Interface Comunicação, Saúde, Educação, 4(7), 25-36. Recuperado em 22 maio, de 2009, de http://www.bahia.com.br/servlet/open?download\&uuid=c293968 6-a119-4499-9204$8 \mathrm{~d} 34 \mathrm{a} 41825 \mathrm{c} 7 \& \&$ property=arquivo_data\&index $=0 \&$ name $=\mathrm{A} \%$ 20contemporane idade $\% 20$ como $\% 20$ idade $\% 20 \mathrm{~m}$ ?dia $\% 20$ \%20Albino\%20Rubim.pdf.

Schilder, P. F. (1999) A imagem do corpo. As energias construtivas da psique (3a ed). São Paulo: Martins Fontes.

Tavares, M. C. G. C. F. (2003). Imagem corporal - Conceito e desenvolvimento. São Paulo: Manole.

\section{REFERÊNCIAS}

Aberastury, A., \& Knobel, M. (1981). Adolescência normal: um enfoque psicanalítico. Porto Alegre: Artmed.

Coste, (1992). Jean Claude. A psicomotricidade (4a ed.). Rio de Janeiro: Zahar. 